\title{
$\mathrm{DJ}$ 解 \\ Volume 7 - Fall 2011 \\ djim.management.dal.ca
}

\section{Consumer Health Information Sources in the 21st Century}

\section{Tracy Daley}

\begin{abstract}
When consumers have health questions, they often seek answers at online sources. Consumer health information is readily available on the Internet but the lack of quality control on the Internet is problematic. This essay examines the following: quality issues associated with online health information, the features and benefits of several consumer health websites, how Web 2.0 innovations can add an interactive layer to basic online consumer health resources, and the role that information professionals play in the field of consumer health information.
\end{abstract}

About the Author(s): Tracy Daley completed a BSc (Hons) in Biology in 2006 at Saint Mary's University in Halifax, Nova Scotia. She is a current candidate in the Master of Library and Information Studies program at Dalhousie University and will graduate in May 2011. Tracy has strong interests in health information and intends to pursue a career in medical librarianship. This essay was originally written for a class called "Information in Society" (INFO5500). 


\section{Introduction}

A 1998 study published in The Lancet led to widespread fear that there was a link between vaccination and autism; however, the study was widely discredited in 2004 and 2005 because other researchers attempted to replicate the results and were unsuccessful (Deer, 2011; Picard, 2011). The Lancet article was retracted by the journal in early 2010 (Deer, 2011). Unfortunately, many members of the public still believe that a link between vaccination and autism exists (Picard, 2011). Likely as a result of these beliefs, the following was posted on the "Autism" page at Wikipedia, for a short period of time on November 28, 2006:

The cause [of Autism] is not fully understood but it is multi-factorial, involving genetics, environmental toxins, and the current mandated vaccine schedule. The risks of vaccines are understated while their benefits overrated. Current practice of combining measles, mumps and rubella into $1 \mathrm{MMR}$ shot greatly increases risk of complications (“Autism." 2006).

This example, which was found by exploring the extensive revision history for the "Autism" article, demonstrates that sources like Wikipedia sometimes contain inaccurate claims and should not be relied upon for health information. Anyone that visited Wikipedia's "Autism" page during the time this statement was posted could have been misinformed into thinking they should not have their child vaccinated. In this case, the page was being monitored and the information was quickly revised. However, this is likely not true of all Wikipedia articles.

Marshall and Williams (2006) summarized the issues of interest to this essay well by stating that "The Internet is unregulated and is perceived to be the area where consumers gain access to information with least guidance from information professionals or health professionals" (p.141). The main goals of this essay are as follows:

1. to outline some of the quality issues associated with online health resources

2. to explain how reputable websites can help consumers find health information that is accurate, complete, unbiased, and up-to-date

3. to discuss how Web 2.0 technologies are changing the face of consumer health on the Internet 
4. to summarize the role that information professionals play in the consumer health field

Please note that the websites discussed here are only a small sample of the multitude of online consumer health resources. The authors aim is to present a few websites that might be of interest to Canadian consumers; however, not all of the websites are produced in Canada.

\section{The availability of health information online}

It is becoming more common for health care systems to encourage patients to take an active role in decision-making related to their health but in order to do so they need to have reliable information on which to base these decisions (Marshall \& Williams, 2006; Canadian Medical Association (CMA), 2010). The unfortunate reality is that often health professionals do not have enough time to help patients understand their health problems (Wofford, Smith \& Miller, 2005). Consumers need easily accessible sources of information to help them answer their health questions. A 2007 survey by Statistics Canada reported that $52.7 \%$ of Canadians have searched for some form of health information on the Internet.

When consumers seek information at Internet search engines, they often fail to find helpful sources of information. Consumers might find sources that are too medically technical and they will not be able to understand the information. Consumers might not find anything that is truly relevant to their query. Possible reasons for a lack of useful search results are the consumer's weak search strategies, the use of slang and spelling errors (Boden, 2009). Eysenbach and Köhler (2002) provide further information on poor search strategies used by consumers. The authors gave focus group participants a health question and asked them to seek an answer using the search engine of their choice. The researchers stated that finding information on the topics assigned would have been easier if the participant used a narrow search strategy. However, it was found that most searches performed were broad, one-term searches (181 out of 280 searches by 16 participants) and that only one participant used Boolean operators to indicate relationships between terms. This study discussed a few instances where consumers found a page that contained the correct answer to a health question (as evaluated by the researchers) but the text was not written in language that was understandable to the participant. In this study, participants were successful in finding answers to the very specific questions used in this study. For example, one question asked "If you want to travel to Australia, do you need malaria prophylaxis?" (p. 574); however, many health information questions are multi-faceted and finding appropriate answers may require an intricate search strategy.

Unfortunately, the health information found on the Internet is often not reliable. Information retrieved via the internet can be biased, misleading and, in some cases, can even be dangerous to the health of the user (Helliwell, 2006). For instance, persistent online advertising campaigns that claim to provide the secret to a quick cure can mislead consumers into buying 
products that might harm their health (Jacobsen, 2008); the product could cause an adverse interaction with a prescribed medication, for example.

\section{The benefits of publically available information resources}

Research articles discussing the benefits associated with online consumer health resources often focus on the information contained at MedlinePlus, which is produced by the U.S. National Library of Medicine (NLM) (a division of the National Institutes of Health). The resource evolved to supply consumers with health information that is authoritative, current and accurate (U.S. National Library of Medicine, 2010a) and the features of this website will be further discussed. This essay continues the trend and uses MedlinePlus as an example, to explain the benefits of publically available health information resources.

\section{Benefits to consumers}

Wofford and colleagues (2005) described the computer as "...a symbol of patient empowerment. Patients view the information revolution, not just as an alternative to personal interactions with physicians but also as a way to improve their relationship with medical professionals..." (p. 150). For example, a study by Olney, Warner, Rayna, Wood and Siegal (2007) reported that seeking information at MedlinePlus has helped consumers formulate questions to ask their doctor and has improved exchanges between the two parties. The authors also indicated that consumers are searching MedlinePlus for information on symptoms they are experiencing, side effects of pharmaceuticals and treatment options for diseases. Study participants reported that knowledge gained at MedlinePlus helped reduce anxiety about a diagnosis or upcoming surgery. For example, several consumers in the study learned that their disease was not as serious as they had feared and that there were treatment options. Furthermore, consumers who took part in a study conducted by Siegel and colleagues (2006) reported that the information found on MedlinePlus helped $93 \%$ of respondents to make betterinformed decisions and $70 \%$ of respondents found that their understanding of a health condition was improved. It is likely that some people experience "information anxiety," as described by Bawden and Robinson (2009), when seeking health information. If they do not know where to look and have trouble understanding the terminology involved, they may feel apprehensive. It seems likely that this unease would result in individuals turning to the very familiar sources they use for information-seeking on any other topic. In North America, this source is likely to be Google, which is the dominant search engine in the region. In the United States Google.com receives over 70\% of all search engine traffic (Experian, 2010). Eysenbach and Köhler (2002) reported results from a series of focus groups that revealed that, indeed, consumers tend to use search engines to seek information on health topics. Among the subjects they studied, many stated that to evaluate the reliability of a website they tend to base their decision on the appearance of the site and the writing style. These users do not tend to 
seek out textual sections that explain who maintains the site or their credentials. A website that aggregates authoritative information, such as MedlinePlus, would be valuable to these individuals.

\section{Benefits to society}

The NLM pays licensing fees for some of the content available on MedlinePlus. However, it provides this content to site visitors at no cost (Miller, Tyler \& Backus, 2004). Everything is free to the public and the only advertising displayed is for other government websites (U.S. National Library of Medicine, 2010b). As a result, MedlinePlus could be considered a "public good," as defined by Lester and Koehler (2007). It can be accessed by several people simultaneously and access by one individual has no influence on another person's ability to gain access. It is available to all members of the public who have access to the Internet. However, certain people who are not able to, or choose not to, access the Internet are excluded from the benefits the site offers. Lester and Koehler (2007) supply the following more specific definition: "A merit good has benefits that accrue to society beyond that gained by the individual who is consuming the good" (p.221). One could argue that MedlinePlus fits this description due to the evidence that suggests that using reliable consumer health resources leads to societal benefits such as more effective preventative medicine and better communication between patients and health providers. The NLM feels that the benefit to society is worth the expense of the licensed content, human resources and the technical infrastructure required to maintain this resource (U.S. National Library of Medicine, 2010c).

\section{Canada lacks an equivalent to MedlinePlus}

Canadian not-for-profit organizations such as the Canadian Cancer Society and the Heart and Stroke Foundation supply excellent information for their respective patient groups. Government websites such as the Public Health Agency of Canada also supply quality consumer information on a wide variety of topics (Consumer Health Information Providers Interest Group, 2010). Across the border, MedlinePlus is a key consumer health website in the United States; it is publically available, it aggregates consumer health information on a broad array of topics from several reputable sources, and it contains no external advertising. Unfortunately, a similar website does not exist in Canada. Furthermore, several Canadian consumer health resources were evaluated in 2004 for reading level and it was found that the language was often too complicated for low-literacy individuals. At this time, it appeared that these sources did not make information in non-text formats such as video or audio a priority (Petch, 2004). As a result, MedlinePlus is a valued resource that is recommended to consumers by information professionals in Canada (Dalhousie University Libraries, 2010).

\section{Basic consumer health online resources vs. Web 2.0- inspired tools}


Basic consumer health websites "meet the fundamental needs of those seeking health information: the need for factual biomedical information about diseases and their causes, symptomology, diagnostic tests, treatment options and prognosis" (Marton, 2011, p. 29). However, their more modern counterparts merge information with Web 2.0 tools that allow users to share their experiences.

\section{Traditional consumer health websites: Reliable but not very engaging}

In Canada, most consumer health websites are focused on a specific disease or population group, rather than covering a broad scope of health topics. The best Canadian websites, as evaluated by the Consumer Health Information Providers Interest Group (2010), include the site produced by the Canada Safety Council, which is a not-for-profit organization with a mandate to educate the public about injury prevention (www.safety-council.org) (Marton, 2011). This website provides high-quality information to visitors but the pages contain mainly static text and the use of Web 2.0 technologies does not appear to be a priority. The only Web 2.0 tool used is Facebook and, up until this point, it is only used to share information with people who have connected with the Council through the Facebook page. It does not appear to effectively promote interactions between the Council and the public or among members of the public. Further, the link to the Facebook page is not placed in a prominent location on the Council's home page (Marton, 2011).

MedlinePlus is an excellent example of an effective consumer health resource that provides information on a wide variety of topics. The content at MedlinePlus is suitable for patients, families and caregivers. Health care providers may also use the site when they require assistance in describing medical conditions in ways that patients can understand. The features of the resource include information on drugs and supplements, a medical encyclopaedia, a medical dictionary with audio for assisting with pronunciation and a section on health topics. The latter section includes information on diseases, disorders and general health topics such as smoking cessation and physical activity (Pullen, Jones, \& Timm, 2010; U.S. National Library of Medicine, 2010b). Each topic has a date indicating the last time it was reviewed for currency and accuracy (Pullen, et al., 2010). The material is written in language that is understandable to consumers with no medical background. Some articles are written at, approximately, a grade 5-8 reading level (U.S. National Library of Medicine, 2010d). MedlinePlus has an assortment of videos relevant to patients (Miller et al., 2004) which are beneficial for patients with low literacy levels or for those who prefer information presented in a visual format rather than in standard text (Miller et al., 2004; Wofford et al., 2005).

As mentioned earlier, one major benefit provided by MedlinePlus is that the content has been evaluated for accuracy and currency. The contributors strive to create accurate and unbiased material. MedlinePlus is linked to many outside sources - all of which have been reviewed by 
the NLM for accuracy and authority. Information from associations such as the American Academy of Family Physicians, American Diabetes Association and Mayo Clinic are examples. The NLM will only recommend outside sources that make it clear that providing health information is their primary goal. Websites that are trying to sell a product or service are not generally considered (Miller et al., 2004).

In the current information environment, in which people are seeking the interaction that Web 2.0 offers, much of the content on the basic consumer health sites is considered trustworthy but not very engaging (Smith \& Mayer, 2009). For example, the NLM has recently started promoting MedlinePlus through the social networking site Twitter (U.S. National Library of Medicine, 2010c), but the Web 2.0 initiative has permeated other online consumer health resources to a much greater degree (Smith \& Mayer, 2009).

\section{Inspired by Web $\mathbf{2 . 0}$}

\section{Interactive tools}

One website that uses a modern approach to providing consumer health information is revolutionhealth.com; here patients can discuss health issues amongst themselves in support groups and forums, read blogs from health professionals, or contact a pharmacist via email (Revolution Health, 2010; Smith \& Mayer, 2009). Users of Revolution Health can also create a health portfolio, and record medical data for future reference. Finally, the site helps users prepare for a visit with a doctor by providing a form where relevant symptoms can be recorded and merged with parts of the user's health portfolio that might need to be consulted during the visit. Most services at Revolution Health are free to the public but the website gains some revenue through special features and through advertising (Mayer, Smith, \& Rios 2008). Further, Revolution Health is targeted at an American audience and therefore some of the services provided, such as the directory of professionals and hospitals, will not be useful for Canadians.

Forward-thinking Canadian consumer health sites include the sites produced by the Canadian Cancer Society (CCS) (http://www.cancer.ca/Canada-wide.aspx?sc_lang=en), the Heart and Stroke Foundation (HSF) (http://www.heartandstroke.com) and a francophone consumer health website known as PasseportSanté (passeportsante.net). All of these organizations have an active social networking presence with interactive posts on their Facebook page and regular updates on their Twitter feed. The CCS and the HSF Facebook pages take advantage of other sharing features, as well. Both pages contain a multitude of photos shared by the CCS and by visitors. At the CCS page, events such as the Relay for Life are promoted. The CCS also has a popular YouTube channel. PasseportSanté also contains blogs by health professionals (Marton, 2011) and an active consumer forum (author observation). 
Smith and Mayer (2009) suggest that if basic sites added Web 2.0 features they could more easily capture the attention of those who seek out interactivity. However, the interactivity between consumers at websites like Revolution Health might contribute to the spread of inaccurate information and consumers need to be made aware of this (Mayer, et al., 2008). Revolution Health indicates on their site that it does not monitor consumer forums and, therefore, the information provided there is not necessarily accurate (Revolution Health, 2007). Joyce Backus from the NLM has reported that "any additional services would also have to be considered against the effort required and NLM's first priority to keep the quality of MedlinePlus as high and consistent as users have come to expect" (Mayer, et al., p. 196).

\section{Health information that "anyone can edit"}

Wikis are one of the key Web 2.0 developments and Wikipedia is the most well-known example (Bawden \& Robinson, 2009). Laurent and Vickers (2009) completed a study designed to determine the frequency with which Wikipedia articles and pages from other sites, such as MedlinePlus, appear in search results on health topics. The authors also examined search results to determine the typical rank of items from Wikipedia and other sites. The study used an automated system to search for hundreds of medical terms at four search engines, including Google.com. Laurent and Vickers (2009) found that Wikipedia ranked within the first ten results on Google.com in about $74 \%$ of searches where MedlinePlus was ranked in the top ten in an average of $43 \%$ of cases. For all of the search engines that they examined, the authors found that Wikipedia articles had a mean position of between 3.05 and 3.40 and MedlinePlus articles had a mean position of between 5.31 and 6.68. The authors examined search statistics to determine which sources were favoured by searchers. The study revealed that Wikipedia links tend to be followed more often than the equivalent page at MedlinePlus. This suggests that Wikipedia appears more prominently to the searcher. Wikipedia is widely used by a large assortment of individuals for information sought on a broad range of topics (Spoetnik, 2009) and, likely, is appealing to persons searching for health information because it is a familiar source. Similar to the conclusion described earlier with reference to search engines, the familiarity may help alleviate anxiety.

According to Spoetnik (2009), a key problem with some health information articles on Wikipedia is omission of necessary information. For example, articles on surgical procedures and drugs have been found to often omit details of side effects and complications. The author also indicates that certain drug companies have been caught altering Wikipedia entries in misleading ways. For example, Rost (2007) reported that employees of Abbott Laboratories have deleted information related to potential safety hazards associated with drugs sold by the company.

On Wikipedia, a "Feature Article" designation is assigned to articles that have been rated as very high quality by anonymous reviewers. However, research by Lindsey (2010) indicates that the system for assigning this designation may be flawed. The author asked subject specialists 
to assess a sample of "Feature Articles" and rate the quality of the information. Of the 22 articles examined, 10 of them were found to have poor or mediocre quality. One of these was the entry on Alzheimer's disease. These results suggest, again, that Wikipedia is not an ideal place to go for health information.

Since 2004, there has been an upsurge in activity on Wikipedia directed at improving Wikipedia articles on health topics. Specifically, WikiProject Medicine consists of Wikipedia editors who are assessing and rating health-related articles ("Wikipedia:WikiProject Medicine," 2011). The current statistics report that of the 25,451 articles assessed so far, 17,723 are considered incomplete ("stubs" and "starts") and only 176 articles have been assessed to be complete and accurate enough to achieve the "Good Article" rating or higher. WikiProject Medicine articles are assigned an importance rating that is used to draw attention to those that are currently in need of work; improvement of articles with a high importance rating is considered a priority. High priority items include those on common diseases and treatments. These particular articles are considered high priority because it is likely there will be people trying to find information on these topics and, therefore, it is considered essential that Wikipedia have a high-quality article on that topic ("Wikipedia: WikiProject Medicine/Assessment," 2011).

Laurent and Vickers (2009) suggested that health professionals adopt Wikipedia articles on their specialty and keep an eye on them to ensure that they are accurate. It is likely that some individuals already perform this function but it is highly doubtful that all subjects are monitored. The fact that anyone can edit the entries leads to problems with quality control. Editors are allowed to remain anonymous and this may lead people to change articles to present views that are not scientifically supported (Bawden \& Robinson, 2009).

\section{Health Literacy and the role of information professionals in consumer health information}

Health literacy is often described as the ability to locate appropriate consumer health resources and evaluate information for relevancy and accuracy. People who are health literate are able to interpret health information in order to understand the symptoms of disease and recognize the worsening symptoms of an existing condition. These individuals tend to be more likely to seek help from health professionals in response to what they have learned (National Network of Libraries of Medicine, 2010). People who learn about their condition also tend to be more confident in discussing treatment options with health professionals because they have a better understanding of the terminology and treatment procedures. It is believed that high rates of health literacy in a population will result in fewer emergency hospitalizations and more preventative procedures such as screenings for certain types of cancer (Olney, et al., 2007). In Canada, it is estimated that 6 out of 10 adults have low health literacy. Rates of health literacy tend to be lower than rates of general literacy because the use of health information is often 
dependent on numeracy skills (Canadian Council on Learning, 2007) and evaluation of information quality (Marshall \& Williams, 2006). Health literacy rates are proportional to health levels in populations; Canadians with a low level of health literacy are 2.5 times more likely to have poor health than Canadians with strong health literacy skills (Canadian Council on Learning, 2007).

Smith and Duman (2009) stated the following on the concept of health literacy: "In order to make an impact on an issue as complex as health literacy, improving one area alone, such as consumer health information, is never going to be enough to make really significant changes" (p. 266). Several authors have described the important role that libraries and information professionals play in improving health literacy in populations and making information more accessible to those with low-health literacy (Helliwell, 2006; Siegel et al., 2006; Smith \& Duman, 2009).

A health sciences librarian can be an invaluable resource for a consumer by providing reliable health information appropriate to the user's needs and abilities (Helliwell, 2006). Information professionals and libraries play a role in supporting consumer health information-seeking by providing access to computers and the Internet, referring consumers to trustworthy sites such as MedlinePlus and assisting consumers with the use of these sites (Siegel et al., 2006). Training programs that instruct consumers on how to use the array of information these sites contain are found to be helpful (Chimato \& Werner, 2006; Trettin, May \& McKeehan, 2008). Chimato and Werner (2006) described a program in which librarians partnered with health professionals to provide training in searching for health information on the Internet, refining a search strategy and evaluating the information found to consumers. Attendees of the program were asked to evaluate the effectiveness and usefulness of the program. The vast majority of attendees indicate that they believe that the information received is highly valuable.

Sometimes professionals are reluctant to attempt to help someone with a health question due to lack of knowledge in the health field but training may help them overcome the apprehension. It follows that opportunities abound for information professionals who are familiar with consumer health resources to help train other professionals in the subject (Carter \& Wallace, 2007). For example, health sciences librarians sometimes deliver training courses for public librarians and public health workers (Carter \& Wallace, 2007; Jacobsen, 2008; Olney et al., 2007). Carter and Wallace (2007) described a program in which 397 employees of public libraries were trained to help consumers with health questions by medical librarians at the East Tennessee State University library.

Libraries have connections to the larger community that are different than those of the health system. As a result, they have knowledge of community organizations and services that may be helpful to the individual seeking consumer health information. Additionally, many consumers would feel that the library would be a more familiar and inviting place to seek health information (Smith \& Duman, 2009). LaValley (2009) describes a program that takes 
advantage of the connections to the community that the public library enjoys in order to promote programs in health literacy and public education on health topics. The program invites health professionals and public health workers to give informational sessions in the library. For example, a specialist in the care of patients with diabetes might deliver a talk on self-care. The author also suggests that libraries provide space for mobile screening services such as cardiovascular health screening.

Some information professionals help educate health professionals in health literacy and partner with them in programs designed to spread the word about reputable consumer health information sources (Jacobsen, 2008). For example, in Skagit Valley in Washington State, medical librarians have delivered training in the basics of health literacy to health professionals (Jacobsen, 2008). Librarians also promote the use of information prescriptions by physicians (Siegel et al., 2006; Jacobsen, 2008). These are similar to prescriptions for pharmaceuticals but they serve to recommend an online source of information. A study by Siegel and colleagues (2006) indicates that prescriptions improve patient education and transfer of information between patients and physicians.

\section{Conclusions}

In the current society, health professionals have little time for patient education and, as a result, patients often seek out information outside of the physician's office. Online consumer health resources can be a valuable resource for patients. The information helps patients understand their condition, become more comfortable discussing health problems with health professionals and reduce anxiety (Olney et al., 2007; Siegal et al., 2006). It is important that the resources supply accurate and up-to-date information. Basic consumer health websites, such as MedlinePlus, deliver on both of these requirements. However, patients also seek communities where they can discuss concerns with real people who either have shared the same experiences or possess the expertise to answer their health questions in an interactive format. So far, MedlinePlus falls short of providing this service but since consumers find both formats useful, they will likely co-exist. Consumers also need to be made aware that sources such as Wikipedia are not always dependable and claims at these sites should be verified. Information professionals will continue to play a role in teaching consumers and other professionals about reliable resources. It will also be important to convey the difference between the various formats described above and, perhaps, help patients decide which is more appropriate to their needs. 


\section{References}

Autism. (2006, November 28). In Wikipedia, The Free Encyclopedia. Retrieved 22:48, January 16, 2011, from http://en. wikipedia.org/w/index.php?title=Autism\&oldid=90569094\#Causes

Bawden, D., \& Robinson, L. (2009). The dark side of information: Overload, anxiety and other paradoxes and pathologies. Journal of Information Science, 35(2), 180-191. DOI: 10.1177/0165551508095781 CrossRef

Boden, C. (2009). Overcoming the linguistic divide: A barrier to consumer health information. Journal of the Canadian Health Libraries Association, 30, 75-80. CrossRef

Canadian Council on Learning. (2007). Health Literacy Interactive. Retrieved from: http://www.cclcca.ca/cclflash/healthliteracy/map help e.html

Canadian Medical Association (CMA). (2010). Health care transformation in Canada: Change that works. Care that lasts. Retrieved from http://www.cma.ca/multimedia/CMA/Content

Images/Inside_cma/Advocacy/HCT/HCT-2010report_en.pdf

Carter, N.J., \& Wallace, R.L. (2008). Collaborating with public libraries, public health departments, and rural hospitals to provide consumer health information services. Journal of Consumer Health on the Internet, 11(4), 1-14. DOI: 10.1300/J381v11n04_01 $\underline{\text { CrossRef }}$

Chimato, M.C., \& Werner, S.E. (2006). Building community relationships. Journal of Hospital Librarianship, 6(2), 15-25. DOI: 10.1300/J186v06n02_02 CrossRef

Consumer Health Information Providers Interest Group. (2010). Top 10 Canadian consumer health websites. Retrieved from: http://www.chla-absc.ca/chipig/Events/CHLA2010poster.pdf

Dalhousie University Libraries. (2010). Evaluation of health information on the Web. Retrieved from http://dal.ca.libguides.com/content.php?pid=88898\&sid=668994

Deer, B. (2011). Secrets of the MMR scare: How the vaccine crisis was meant to make money. BMJ, 342:c5258. DOI: 10.1136/bmj.c5258. CrossRef

Experian. (2010, November 6). Top 20 sites \& engines. Retrieved from http://www.hitwise.com/us/datacenter/main/dashboard-10133.html

Eysenbach, G., \& Köhler, C. (2002). How do consumers search for an appraise health information on the world wide web? Qualitative study using focus groups, usability tests, and in-depth interviews. British Medical Journal, 324(7337), 573-577. CrossRef

Helliwell, M. (2006). Comfy chairs, lovely books, and no librarian: What is the professional standard for setting up a CHIS? Journal of Hospital Librarianship, 7 (1), 53-62. DOI: 10.1300/J186v07n01_05 CrossRef 
Jacobsen, S. (2008). GetHELP health literacy in Skagit Valley, WA. Journal of Hospital Librarianship, 8(1), 53-60. DOI: 10.1080/15323260801931955 CrossRef

Laurent, M.R., \& Vickers, T.J. (2009). Seeking health information online: Does Wikipedia matter? Journal of the American Medical Informatics Association, 16(4), 471-479. DOI: 10.1197/jamia.M3059 CrossRef

LaValley, S. (2009). Delaware health source: Consumer health libraries and health literacy outreach. Journal of Consumer Health on the Internet, 13(2), 180-186. DOI: 10.1080/15398280902897103 CrossRef

Lester, J., \& Koehler, W. C. Jr. (2007). The economics of information. In Fundamentals of information studies: Understanding information and its environment (2nd ed.). (pp. 219-240). New York: Neal-Schuman Publishers.

Lindsey, D. (2010). Evaluating quality control of Wikipedia's feature articles. First Monday, 15(4). Retrieved from http://www.uic.edu/htbin/cgiwrap/bin/ojs/index.php/fm/article/view/2721/2482

Marshall, L. A., \& Williams, D. (2006). Health information: Does quality count for the consumer? How consumers evaluate the quality of health information materials across a variety of media. Journal of Librarianship and Information Science, 38(3), 141-156. $\underline{\text { CrossRef }}$

Marton, C. (2011). Consumer health 2.0 in Canada: A descriptive analysis of the use of Web 2.0 technologies on Canadian consumer health information websites. Journal of the Canadian Health Libraries Association, 32, 29-34. Retrieved from http://pubs.chla-absc.ca/journal/jchla CrossRef

Mayer, S., Smith, K.H. \& Rios, G. (2008). Consumer health information services 2.0. Journal of Consumer Health on the Internet, 12(3), 187-199. CrossRef

Miller, N., Tyler, R.J., \& Backus, J.E.B. (2004). MedlinePlus®: The National Library of Medicine® brings quality information to health consumers. Library Trends, 53(2), 375-388.

National Network of Libraries of Medicine. (2010). Health literacy. Retrieved from http://nnlm.gov/outreach/consumer/hlthlit.html

Olney, C.A., Warner, D.G., Rayna, G., Wood, F.B., \& Siegel, E.R. (2007). MedlinePlus and the challenge of low health literacy: findings from the Colonias project. Journal of the Medical Library Association, 95(1), 31-39.

Petch, T. (2004). Content analysis of selected health information websites. Retrieved from http://ir.lib.sfu.ca/handle/1892/4038

Picard, A. (2011, February 6). Medical fraud revealed in discredited vaccine-autism study. The Globe and Mail. Retrieved from http://www.theglobeandmail.com 
Pullen, K.A., Jones, D., \& Timm, D.F. (2010). Healthy connections for consumers: National Library of Medicine websites. Poster presented at the meeting of the Medical Library Association, Washington, D.C.

Revolution Health. (2010). Community. Retrieved from http://www.revolutionhealth.com

Revolution Health. (2007). Posting guidelines. Retrieved from http://www.revolutionhealth.com/about/posting-guidelines

Rost, P. (2007, August 30). Abbott caught altering entries to Wikipedia [Web log message]. Retrieved from http://www.brandweeknrx.com/2007/08/abbott-caught-a.html

Siegel, E.R., Logan, R.A, Harnsberger, R.L., Cravedi, K., Krause, J.A., Lyon, B., Hajarian, K., Uhl, J., Ruffin, A., \& Lindberg, D.A.B. (2006). Information Rx: Evaluation of a new informatics tool for physicians, patients, and libraries. Information Services \& Use, 26, 1-10.

Spoetnik, L. (2009, September 14). The Trouble with Wikipedia as a Source for Medical Information [Web log message]. Retrieved from http://laikaspoetnik.wordpress.com/2009/09/14/the-troublewith-wikipedia-as-a-source-for-medical-information/

Smith, S., \& Duman, M. (2009). The state of consumer health information: an overview. Health Information and Libraries Journal, 26, 260-278. DOI:10.1111/j.1471-1842.2009.00870.x CrossRef

Smith, K.H. \& Mayer, S. (2009). The "Big Three" consumer health sites and web technology trends: MedlinePlus, Healthfinder, and CAPHIS. Journal of Consumer Health on the Internet, 13(3), 213-222. DOI: $10.1080 / 15398280903119705$ CrossRef

Statistics Canada. (2007). Internet users who reported searching for medical or health-related information [Data file]. Retrieved from CANSIM using CHASS database, University of Toronto on November 14, 2010.

U.S. National Library of Medicine. (2010a). MedlinePlus quality guidelines. Retrieved from http://www.nlm.nih.gov/medlineplus/criteria.html

U.S. National Library of Medicine. (2010b). About MedlinePlus. Retrieved from http://www.nlm.nih.gov/medlineplus/aboutmedlineplus.html

U.S. National Library of Medicine. (2010c). Congressional Justification FY2011. Retrieved from http://www.nlm.nih.gov/about/2011CJ.html

U.S. National Library of Medicine. (2010d). MedlinePlus FAQ: Easy-to-read documents. Retrieved from http://www.nlm.nih.gov/medlineplus/faq/easytoread.html

Trettin, L.D., May, J.C., \& McKeehan, N. (2008). Teaching teens to "Get Net Smart for Good Health": Comparing interventions for an Internet training program. Journal of the Medical Library Association, 96(4), 370-374. DOI: 10.3163/1536-5050.96.4.013 CrossRef 
Wikipedia:WikiProject Medicine. (2011, April 14). In Wikipedia, The Free Encyclopedia. Retrieved 14:35, April 24, 2010 from http://en.wikipedia.org/wiki/Wikipedia:WikiProject Medicine

Wikipedia:WikiProject Medicine/Assessment. (2011, April 3). In Wikipedia, The Free Encyclopedia. Retrieved 13:53, April 24, 2010 from http://en.wikipedia.org/wiki/Wikipedia:WikiProject Medicine/Assessment

Wofford, J.L., Smith, E.D., \& Miller, D.P. (2005). The multimedia computer for office-based patient education: a systematic review. Patient Education and Counseling, 59, 148-157. doi:10.1016/j.pec.2004.10.011 CrossRef 